\title{
Strong pulse effects of precipitation events on soil microbial respiration in temperate forests
}

\author{
Wang Qing ${ }^{\mathrm{a}, \mathrm{b}}$, He Nianpeng ${ }^{\mathrm{a}, *}$, Liu Yuan ${ }^{\mathrm{a}}$, Li Meiling ${ }^{\mathrm{a}}, \mathrm{Xu}^{\mathrm{a}}{ }^{\mathrm{a}}$ \\ a Key Laboratory of Ecosystem Network Observation and Modeling, Institute of Geographic Sciences and Natural Resources Research, Chinese Academy of Sciences, Beijing 100101, China \\ ${ }^{\mathrm{b}}$ Agricultural University of Anhui, Hefei 230036, China
}

\section{A R T I C L E I N F O}

\section{Article history:}

Received 11 August 2015

Received in revised form 17 April 2016

Accepted 19 April 2016

Available online 4 May 2016

\section{Keywords:}

Forest soil

High-resolution measurements

Precipitation event

Soil respiration

Wetting-drying cycling

\begin{abstract}
A B S T R A C T
Precipitation is a critical factor triggering soil biogeochemical processes in arid and semi-arid regions. In this study, we selected soils from two temperate forests-a mature natural forest and a degraded secondary forest-in a semi-arid region. We investigated the pulse effects of simulated precipitation (to reach $55 \%$ soil water-holding capacity) on the soil microbial respiration rate $\left(R_{\mathrm{S}}\right)$. We performed high-intensity measurements (at 5-min intervals for $48 \mathrm{~h}$ ) to determine the maximum value of $R_{\mathrm{S}}\left(R_{\mathrm{S}-\max }\right)$, the time to reach $R_{\mathrm{S} \text {-max }}\left(T_{R_{S-\max }}\right)$, and the duration of the pulse effect (from the start to the end of $1 / 2 R_{\mathrm{S} \text {-max }}$ ). The responses of $R_{\mathrm{S}}$ to simulated precipitation were rapid and strong. $R_{\mathrm{S}-\max }$ was significantly higher in degraded secondary forest $\left(18.69 \mu \mathrm{g} \mathrm{Cg} \mathrm{soil}{ }^{-1} \mathrm{~h}^{-1}\right)$ than in mature natural forest ( $7.94 \mu \mathrm{g} \mathrm{Cg}$ soil ${ }^{-1} \mathrm{~h}^{-1}$ ). In contrast, the duration of the pulse effect and $T_{R_{\text {s-max }}}$ were significantly lower in degraded secondary forest than in mature natural forest. Furthermore, the accumulative microbial respiration per gram of soil $\left(A_{R_{\text {s-soil }}}\right)$ did not differ significantly between degraded secondary forest and mature natural forest, but the accumulative microbial respiration per gram of soil organic $\mathrm{C}\left(A_{R_{5-5 o c}}\right)$ was significantly higher in degraded secondary forest than in mature natural forest. Soil microbial biomass, soil nutrient, and litter nitrogen content were strongly correlated with the duration of the pulse effect and $T_{R_{\text {s-max }}}$. Soil physical structure, $\mathrm{pH}$, and litter nitrogen content were strongly correlated with $R_{\mathrm{S} \text {-max }}$ and $A_{R_{\mathrm{S}-\mathrm{soc}}}$. Our results indicate that the responses of soil microbial respiration to simulated precipitation are rapid and strong and that microbial respiration rate per gram C can be used to precisely determine the precipitation pulse of different soil samples as well as the effects of changing precipitation patterns on soil C content under various scenarios of global climate change.
\end{abstract}

(c) 2016 Elsevier B.V. All rights reserved.

\section{Introduction}

Precipitation events trigger a cascade of biogeochemical transformations in soils, thereby leading to a hierarchy of soil moisture pulse events and corresponding ecological responses (Schwinning and Sala, 2004a). The pulse effects of precipitation can result in rapid release of nutrients (within minutes or hours) by soil microorganisms (Cui and Caldwell, 1997); moreover, at longer time scales (years), they may influence the responses of primary producers and consumers (Ostfeld and Keesing, 2000). The phenomena that rewetting of dry soils results in a pulse of carbon $(\mathrm{C})$ and nitrogen $(\mathrm{N})$ mineralization have been termed the Birch effect (Birch, 1958). The soil microbial respiration rate $\left(R_{\mathrm{S}}\right)$ has been shown to vary according to the frequency and intensity of precipitation (Schwinning and Sala, 2004a; Kim et al., 2012). In general, the pulse effects of precipitation depend on: the following factors (1) the previous status of soil water content; (2) the precipitation intensity; and (3) precipitation frequency. In addition, soil type and quality, vegetation, and duration of precipitation have been reported to modify the pulse effect (Schwinning et al., 2004b).

\footnotetext{
* Corresponding author.

E-mail address: henp@igsnrr.ac.cn (N. He).
}

Some studies have reported that simulated precipitation (or rewetting) can enhance $R_{\mathrm{S}}$ relative to soil under drought conditions (Davidson et al., 2000; Fierer and Schimel, 2003). This pulse effect can increase cumulative $\mathrm{CO}_{2}$ release by more than three-fold relative to soils with a stable moisture regime (Miller et al., 2005). Furthermore, intra-seasonal precipitation patterns-such as precipitation intensity, frequency, and time-can influence the biological processes in soils, especially in water-limited ecosystems (Schwinning et al., 2003). Small precipitation events may facilitate the respiration of biological crust C, whereas large precipitation events may primarily promote the respiration of microbial C (Cable and Huxman, 2004; Schwinning and Sala, 2004a).

Arid and semi-arid ecosystems are particularly sensitive to precipitation, because important resources (e.g., water and nutrients) are discontinuously available for long periods under discrete precipitation events. While the pulse effects of precipitation events on $R_{\mathrm{S}}$ are known to be important for soil nutrient cycles and soil organic matter (SOM) turnover in semi-arid and arid regions, these effects have not yet been well elucidated (Huxman et al., 2004; Kim et al., 2012; Sala and Lauenroth, 1982; Sponseller, 2007). Iovieno and Baath (2008) have found that the responses of $R_{\mathrm{S}}$ to precipitation events are rapid, and $R_{\mathrm{S}}$ can return to background levels within a short time (e.g., 1 h). However, most studies 
have been conducted at relatively long measurement intervals, such as hours (Butterly et al., 2010; Rudaz et al., 1991; Sponseller, 2007), days, or weeks (Chowdhury et al., 2011; Wu and Brookes, 2005). Owing to the lack of measurements at the scale of seconds or minutes, the pulse effects of precipitation on $R_{\mathrm{S}}$ remain less understood.

Various explanations have been proposed for the observed pulse effects of precipitation. Some researchers have suggested that the availability of physically protected SOM to microbes is enhanced after precipitation because of changes in the soil structure (Göransson et al., 2013; Iovieno and Baath, 2008). Jones and Murphy (2007) reported that with substrate addition, activation of soil microbes occurred almost instantaneously (within $<60 \mathrm{~s}$ ), and that the average time to halfmaximum $\mathrm{CO}_{2}$ production was $10-14 \mathrm{~min}$, which demonstrated the important effect of substrate indirectly. Another alternative explanation is a rapid increase in soil microbial biomass after precipitation (Evans and Wallenstein, 2012; Lundquist et al., 1999; Manzoni et al., 2014; Meisner et al., 2013). Fierer and Schimel (2003) labeled soils with 14C-glucose and showed that the pulse of $\mathrm{CO}_{2}$ emission was generated from the mineralization of microbial biomass C. Butterly et al. (2009) demonstrated that the intensity of $R_{\mathrm{S}}$ after simulated precipitation was highest in the treatment with the largest and most active biomass via substrate addition. Collectively, these findings suggest that soils with more microbes and available substrate have stronger pulse effects and produce larger quantities of $\mathrm{CO}_{2}$.

In this study, we conducted incubation experiments using forest soils from two temperate forests-a mature natural forest and a degraded secondary forest-in a semi-arid temperate region. We performed high-intensity measurements ( 272 times for $48 \mathrm{~h}$ ) to investigate the pulse effects of simulated precipitation on $R_{\mathrm{S}}$. Our specific objectives for the present study were as follows: (1) to investigate the dynamics of pulse effects on $R_{\mathrm{S}}$ in response to precipitation events; (2) to examine the differences of pulse effects (e.g., reactive intensity and durability) between mature natural forest and degraded secondary forest soils; and (3) to investigate how microbial biomass and vegetable type contribute to the observed pulse effects in these different temperate forest soils.

\section{Materials and methods}

\subsection{Site description}

The experimental plots used in the study were located west of Beijing at an average elevation of $1330 \mathrm{~m}$ (Hou et al., 2006). This region has a temperate continental monsoon climate and the mean annual temperature and precipitation are $11{ }^{\circ} \mathrm{C}$ and $639 \mathrm{~mm}$, respectively. The regional soils are classified as Lixisols, according to the classification of world reference base for soil resources (Phillips and Marion, 2007).

We collected soils from two temperate forests-a mature natural forest and a degraded secondary forest. The mature natural forest was located at $39^{\circ} 57^{\prime} \mathrm{N}, 115^{\circ} 25^{\prime} \mathrm{E}$, and the dominant tree species were Quercus wutaishanica, Betula platyphylla, and Larix principis-rupprechtii. The contents of soil organic carbon (SOC) and total N (TN) were $4.01 \%$ and $0.30 \%$, respectively. The soil particle size distribution was $78 \%$ sand, $21 \%$ silt, and $1 \%$ clay (He et al., 2009). The degraded secondary forest was located at $39^{\circ} 58^{\prime} \mathrm{N}, 115^{\circ} 26^{\prime} \mathrm{E}$, and the dominant plant species were secondary shrubs such as Corylus mandshurica, Abelia biflora, and Fraxinus rhynchophylla. The contents of SOC and TN were $3.46 \%$ and $0.26 \%$, respectively. The particle size distribution was approximately $25 \%$ sand, $69 \%$ silt, and $6 \%$ clay (He et al., 2009). Additional details regarding the two forests are shown in Table 1.

\subsection{Field sampling}

Soil sampling was conducted during September 2014. Four experimental plots ( $30 \mathrm{~m} \times 40 \mathrm{~m}$ ) were established in each forest. Soil samples

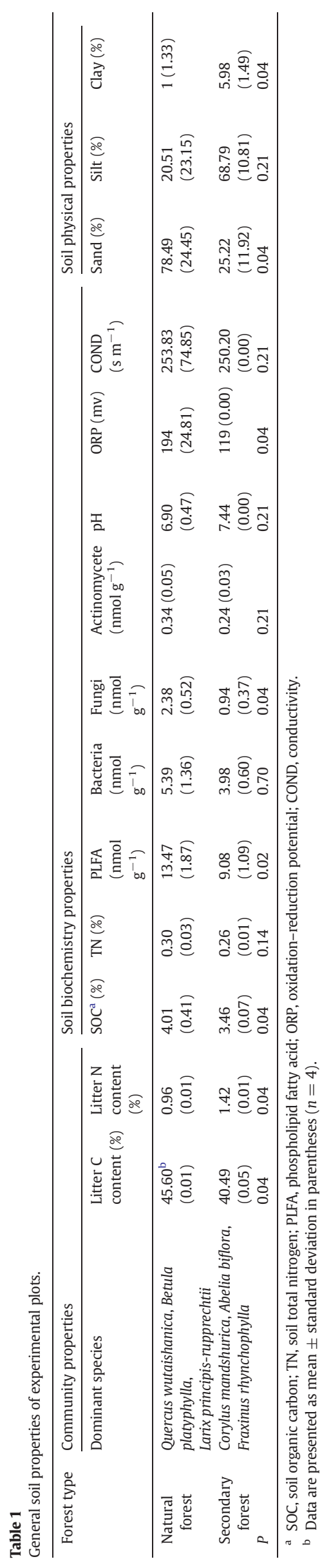


(0-10 cm depth) were randomly collected at each plot. In the laboratory, the soil samples were sieved ( $<2 \mathrm{~mm}$ diameter), and roots and visible organic debris were removed by hand. For each plot, approximately $1 \mathrm{~kg}$ of fresh soil was refrigerated at $-20^{\circ} \mathrm{C}$ for measurement of microbial properties, and $2 \mathrm{~kg}$ of fresh soil were stored at $4{ }^{\circ} \mathrm{C}$ for the incubation experiments. Approximately $500 \mathrm{~g}$ of fresh soil from each plot were air-dried for analysis of soil properties.

\subsection{Laboratory analysis of soil properties}

We measured water-holding capacity (WHC, \%) using a simple substitute for the soil core method (He et al., 2013). In brief, soil samples were placed in a dense screen mesh and soaked in distilled water for approximately $12 \mathrm{~h}$. Then, the samples were placed in a dark, unvented cabinet for approximately $8 \mathrm{~h}$ and were then weighed before and after drying for $48 \mathrm{~h}$ in an oven at $105^{\circ} \mathrm{C}$. Particle size distribution was determined using wet-sieving methods as the previously described (Roscoe et al., 2000; He et al., 2009). The contents of soil C and $\mathrm{N}$ were measured using an elemental analyzer (Elementar Vario Max, Germany). Soil pH, oxidation-reduction (redox) potential, and conductivity were determined using a pH meter (Mettler Toledo Delta 320 , Switzerland) in a slurry of soil and distilled water (1:2.5). Dissolved organic $\mathrm{N}$ was measured using a continuous flow analyzer (Futura, France).

The phospholipid fatty acid (PLFA) content was determined using mild alkaline methyl esterification (Baath and Anderson, 2003). The samples were analyzed using a Thermo ISQ gas-chromatography mass-spectrometry system (TRACE GC Ultra ISQ, Germany). The lipids were extracted from $8 \mathrm{~g}$ of dry-weight-equivalent fresh soil using chloroform:methanol:phosphate buffer (1:2:0.5). The individual compounds were identified by comparing their relative retention times with 37 commercially available FAMEs (FAME 37 47885-U, Supelco Inc.) and a mixture of 26 bacterial FAMEs (BAME 26 47080-U, Supelco Inc.). The concentrations of the individual compounds were obtained by comparing the peaks with an internal standard (nonadecanoic acid methyl ester 19:0). The sum of all PLFAs was used to represent the viable microbial biomass (Xu et al., 2015; Table 1).

\subsection{Design of the incubation experiment}

Soil samples used in the incubation experiment were air-dried at room temperature for approximately 1 week until the soil water content was $<10 \%$ of WHC. Before the experiment, $10 \mathrm{~g}$ samples of each air-dry soil were placed in incubation bottles $(5 \mathrm{~cm}$ diameter, $10 \mathrm{~cm}$ height), with 28 replicates for each forest type (four replicates for measuring the microbial respiration rate $\left(R_{\mathrm{S}}\right)$ and 24 replicates for six timedestructive measurements of microbial biomass $\mathrm{N}$ and dissolved organic N). Then, all air dried soil samples were rewetted to 55\% WHC using a sprayer to stimulate precipitation under an incubator with a constant temperature of $22^{\circ} \mathrm{C}$; then $R_{\mathrm{S}}$ and microbial biomass $\mathrm{N}$ and dissolved organic $\mathrm{N}$ were measured over $48 \mathrm{~h}$, respectively, as described in Section 2.5. Furthermore, soil water content in the incubation bottles was measured at 0 h, 1 h, 2 h, 4 h, 8 h, 12 h, 24 h, 26 h, 28 h, 30 h, $32 \mathrm{~h}, 34 \mathrm{~h}, 36 \mathrm{~h}$, and $48 \mathrm{~h}$ after simulated precipitation using the weighing method by an electronic balance. All data were converted to soil water content values. We used a previously described procedure (He et al., 2013) to simulate the process of dry-rewetting-drying over $48 \mathrm{~h}$ after precipitation.

\subsection{Measurement of soil microbial respiration rate $\left(R_{S}\right)$}

For intensively measuring the $R_{\mathrm{S}}$, we adopted continuousmeasurement equipment developed by He et al. (2013); this equipment can rapidly measure the $R_{\mathrm{S}}$ of each incubation bottle per sample per $75 \mathrm{~s}$. Therefore, we measured the dynamics of $R_{\mathrm{S}}$ for each replicate at 5-min intervals during the $48 \mathrm{~h}$ incubation period. $R_{\mathrm{S}}$ was calculated based on the slope of the change in $\mathrm{CO}_{2}$ concentration and conversion factors (He et al., 2013) as follows:

$R_{\mathrm{S}}=\frac{C \times V \times \alpha \times \beta}{m}$

where $R_{\mathrm{S}}$ is the soil microbial respiration rate ( $\mu \mathrm{g} \mathrm{C}$ g soil $\left.{ }^{-1} \mathrm{~h}^{-1}\right) ; C$ is the slope of the change in $\mathrm{CO}_{2}$ concentration; $V$ is the volume of the incubation bottle and gas tube; $m$ is the soil weight $(\mathrm{g}) ; \alpha$ is the conversion coefficient for $\mathrm{CO}_{2}$ mass (12/44, from $\mathrm{CO}_{2}$ to $\left.\mathrm{C}\right)$; and $\beta$ is a conversion coefficient of time (3600, from s to h) (Wang et al., 2016).

\subsection{Characterization of the pulse effects of the precipitation event}

We depicted the pulse effects of the precipitation event using four parameters as follows: $R_{\mathrm{S} \text {-max }}$ [maximum microbial respiration rate ( $\mu \mathrm{g} \mathrm{C} \mathrm{g} \mathrm{soil}{ }^{-1} \mathrm{~h}^{-1}$ )]; $T_{R_{\mathrm{S}-\max }}$ [time to reach $R_{\mathrm{S}-\max }(\mathrm{h})$ ]; duration of the pulse effect [duration of the pulse from the start to the end of $1 / 2 R_{\mathrm{S} \text {-max }}(\mathrm{h})$ ]; and $A_{\mathrm{RS}}$ [accumulative emission of $R_{\mathrm{S}}$ during the $48 \mathrm{~h}$ incubation period].

We initially calculated $A_{\mathrm{RS}}$ on the basis of soil weight $\left(A_{R_{\mathrm{S}-\text { soil }}}\right.$, $\mu \mathrm{g} \mathrm{C} \mathrm{g} \mathrm{soil}{ }^{-1}$ ) as follows:

$A_{\mathrm{RS}-\text { soil }}=\frac{\sum_{i}^{48} \frac{R_{\mathrm{S}-t_{i}}+R_{\mathrm{S}-t_{i+1}}}{2} *\left(t_{i+1}-t_{i}\right)}{m}$

where $t_{i}$ and $t_{i+1}$ are different measurement times (h).

According to the significant difference in SOC content between the two forest soils, we also calculated $A_{\mathrm{RS}}$ based on the SOC content; we designated this term as $A_{R_{\mathrm{S}-\mathrm{soc}}}\left(\mu \mathrm{g} \mathrm{Cg} \mathrm{SOC}{ }^{-1}\right.$ ) (Shi and Marschner, 2014):

$A_{\mathrm{Rs}-\mathrm{SOC}}=\frac{\sum_{i}^{48} \frac{R_{\mathrm{S}-t_{i}}+R_{\mathrm{S}-t_{i+1}}}{2} *\left(t_{i+1}-t_{i}\right)}{m \times c}$

where $c$ is the SOC content (\%).

\subsection{Determination of soil microbial biomass $N$}

Synchronizing with measuring microbial respiration, we measured changes in soil microbial biomass $\mathrm{N}$ in four replicate samples for each forest after incubation for $0 \mathrm{~h}, 1 \mathrm{~h}, 8 \mathrm{~h}, 12 \mathrm{~h}, 24 \mathrm{~h}$, and $48 \mathrm{~h}$ at $22^{\circ} \mathrm{C}$. The destructive soil samples were divided into two sets-fumigated (chloroform) and non-fumigated. We calculated the biomass $\mathrm{N}$ ( $\mathrm{mg} \mathrm{N} \mathrm{kg} \mathrm{soil}{ }^{-1}$ ) as the difference between $\mathrm{N}$ extracted from the fumigated and non-fumigated samples $(\mathrm{Kn}=0.54)$, following the protocol of Brookes et al. (1985). In brief, the fumigated and non-fumigated samples were extracted with $50 \mathrm{~mL}$ of $\mathrm{K}_{2} \mathrm{SO}_{4}$ solution and shaken simultaneously for $1 \mathrm{~h}$. After shaking, the suspensions were allowed to settle for $10 \mathrm{~min}$ and the supernatants were filtered through a membrane pore size of $0.45 \mu \mathrm{m}$. The supernatants were measured using a continuous flow analyzer (Futura, France).

\subsection{Statistical analysis}

We used the Kolmogorov-Smirnov nonparametric test to identify significant differences in soil properties between the mature natural forest and the degraded secondary forest and significant differences in the properties of pulse effects $\left(R_{\mathrm{S} \text {-max }}, T_{R_{\mathrm{S} \text {-max }}}\right.$ duration of the pulse effect, $A_{R_{\text {S-soil }}}$ and $\left.A_{R_{\text {S-soc }}}\right)$. We performed the statistical analyses using SPSS version 18 (SPSS Inc., Chicago, IL). We conducted redundancy analysis (RDA) to examine the relationships between influencing factors and pulse properties. Before conducting RDA, we selected significantly correlated factors into the stepwise regression and applied the Monte 
Carlo permutation test. The RDA and stepwise regression data were processed using CANOCO software version 4.5.

\section{Results}

\subsection{Pulse effects of simulated precipitation}

The simulated precipitation event significantly enhanced $R_{\mathrm{S}}$ and triggered an apparent pulse effect on microbial respiration. For each soil, $R_{\mathrm{S}}$ values were very low before the simulated precipitation event, but increased immediately after precipitation (Fig. 1A, B). The values of $R_{\mathrm{S}-}$ ${ }_{\max }$ for the mature natural forest and degraded secondary forest were $7.94 \pm 0.16 \mu \mathrm{g} \mathrm{C} \mathrm{g} \mathrm{soil}{ }^{-1} \mathrm{~h}^{-1}$ and $18.69 \pm 1.24 \mu \mathrm{g} \mathrm{C} \mathrm{g} \mathrm{soil}{ }^{-1} \mathrm{~h}^{-1}$, respectively; these values are approximately 10 - to 100 -fold higher than those of dry soil before precipitation.

$R_{\mathrm{S} \text {-max }}$ differed significantly between the two forests $(P<0.05)$. The values of $T_{R_{\mathrm{S}-\mathrm{max}}}$ for degraded secondary forest soil and mature natural forest soil were $5.4 \mathrm{~min}(0.09 \mathrm{~h})$ and $18.6 \mathrm{~min}(0.31 \mathrm{~h})$, respectively (Fig. 2). The time to recover to background was longer in the mature natural forest (2 days) than in the degraded secondary forest (1.3 days). The value of $A_{R_{\mathrm{s}-\text { soil }}}$ did not differ significantly between the two forest soils ( $P=0.27$, Fig. $3 \mathrm{~B}$ ); however, the value of $A_{R_{\mathrm{s}-\mathrm{soc}}}$ was significantly higher in degraded secondary forest soil than in mature natural forest soil $(P<0.001$, Fig. 3A).

\subsection{Factors influencing variation in pulse effect}

The response of microbial biomass $\mathrm{N}$ to simulated precipitation was more marked in degraded secondary forest soil than in mature natural forest soil (Fig. 4A). Distinct differences in the pulse effect between the two forest soils were revealed in the RDA result (Fig. 5). The first and second canonical axes explained $99.7 \%$ and $0.3 \%$, respectively, of the total variance in pulse effect. The results of the Monte Carlo permutation test revealed that the 14 investigated soil properties together explained $99 \%$ of the total variance of pulse properties.

$R_{\mathrm{S}-\max }$ and $A_{R_{\mathrm{S}-\mathrm{soc}}}$ were strongly positively correlated with silt, sand, and litter $\mathrm{N}$ content, and negatively correlated with litter $\mathrm{C}$ content and clay (Fig. 5). Contrasting relationships were observed for the duration of the pulse effect. In addition, $A_{R_{\mathrm{S}-\text { soil }}}$ was strongly negatively correlated with $\mathrm{pH}$, and $T_{R_{\mathrm{S}-\max }}$ was strongly positively correlated with ORP and negatively correlated with pH (Fig. 5).

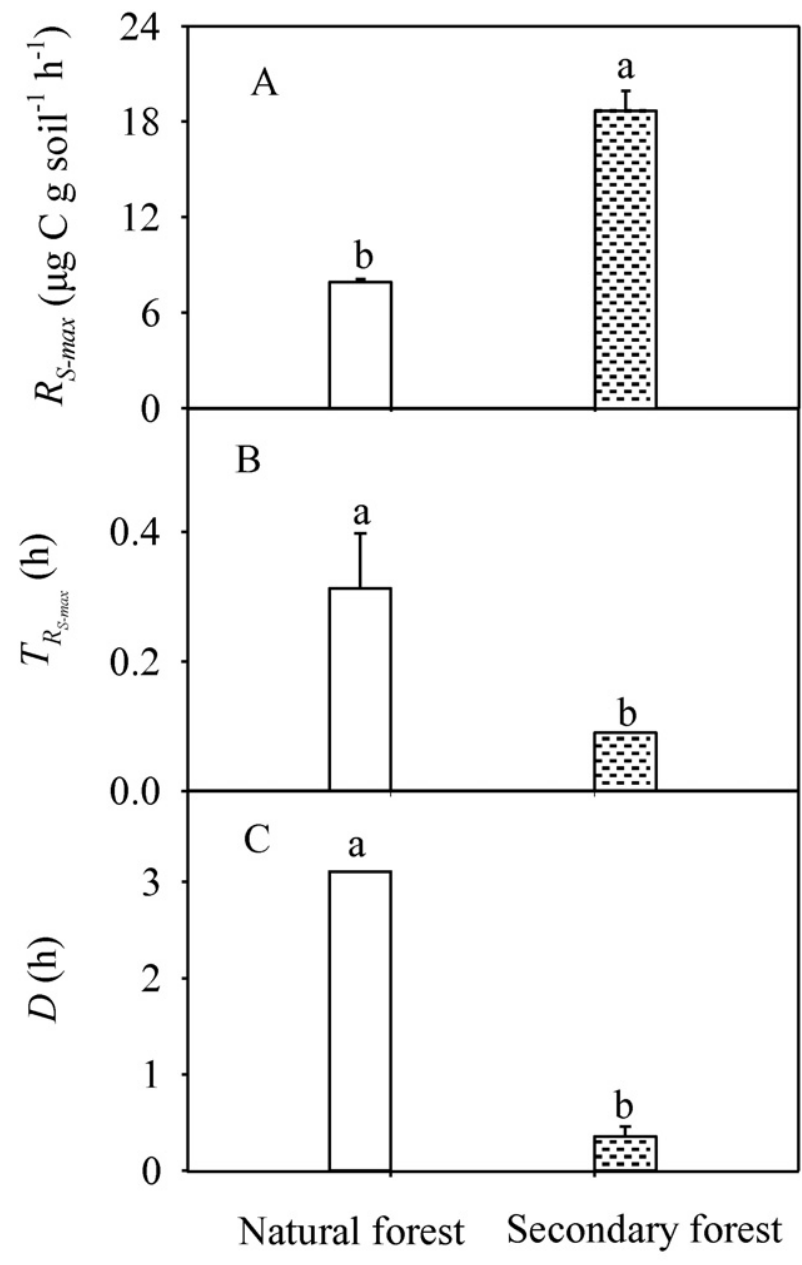

Forest type

Fig. 2. The pulse effects of precipitation on microbial respiration in different forest types. $R_{\mathrm{S}-\max }$, maximum soil microbial respiration rate $(\mathrm{A}) ; T_{R_{\mathrm{S}-\max }}$ time to reach $R_{\mathrm{S}-\max }(\mathrm{B}) ; D$ duration of pulse from the start to the end of $1 / 2 R_{\text {S-max }}(C)$. Error bars represent SD $(n=4)$. Different lowercase letters indicate significant differences at $P=0.05$.

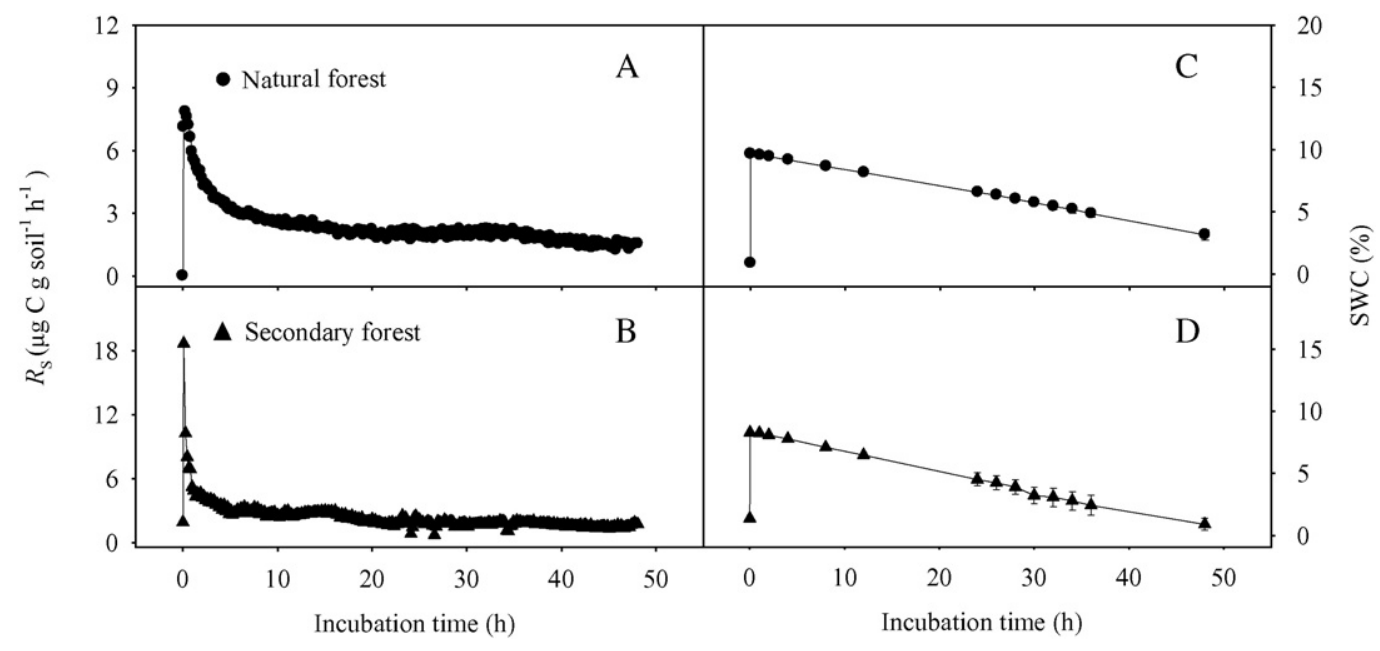

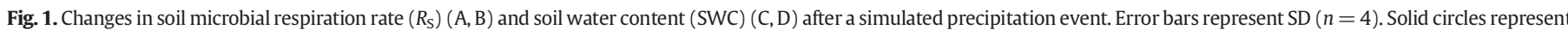
mature natural forest; solid triangles represent degraded secondary forest. 


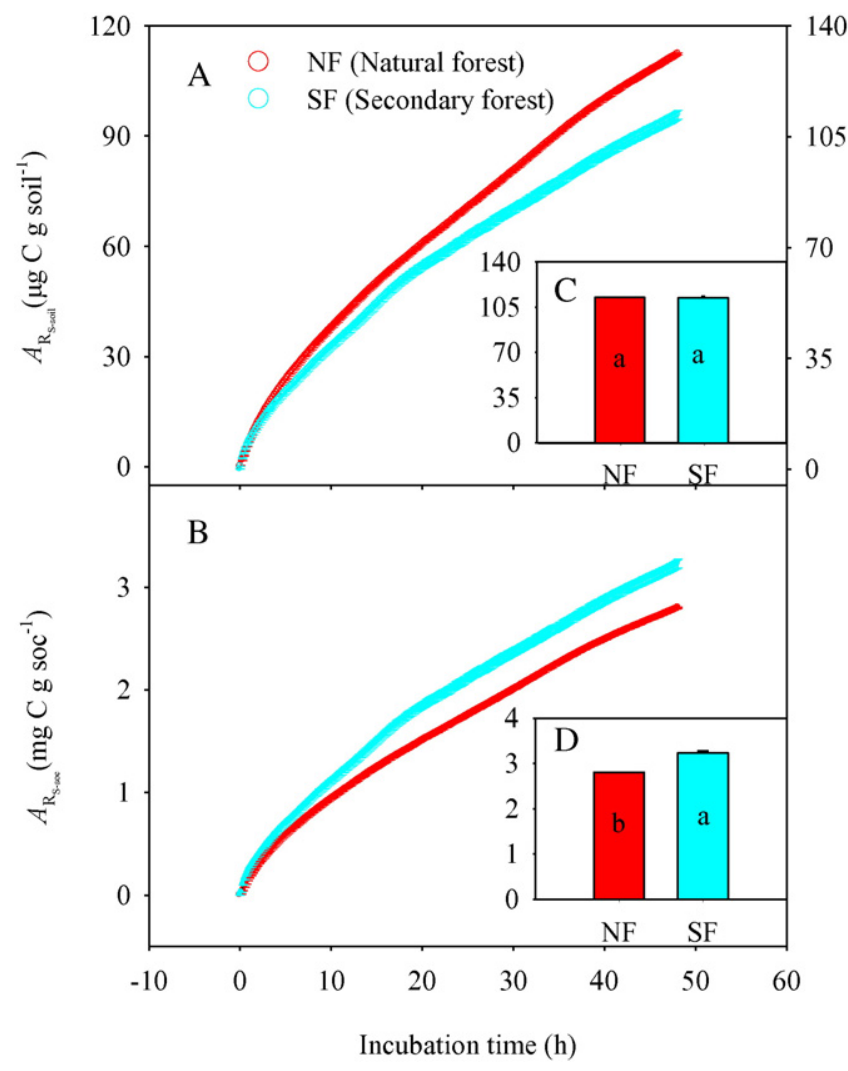

Fig. 3. Accumulative soil microbial respiration after simulated precipitation event. (A) Accumulative soil respiration per gram of soil $\left(A_{R_{\text {s-soil }}}\right)$ according to incubation time (h); (B) Accumulative soil respiration per gram of soil organic carbon $\left(A_{R_{\mathrm{S} s \mathrm{soc}}}\right)$ according to incubation time (h). Data in inset panels (C) and (D) show total $A_{R_{\text {S-sool }}}$ and $A_{R_{\text {S-soc }}}$ during the 48-h incubation period. Different lowercase letters indicate significant differences at $P=0.05$. Error bars represent $\operatorname{SD}(n=4)$.

\section{Discussion}

\subsection{Rapid and strong pulse effects of precipitation}

In this study, the simulated precipitation event induced a rapid and strong pulse effect on $R_{\mathrm{S}}$ in temperate forest soils and $R_{\mathrm{S} \text {-max }}$ was observed within approximately 10-20 min. The observed $R_{\mathrm{S}}$ values after the simulated precipitation were approximately 10-100-fold higher than those of dry soils before the event; this increase was more marked



Fig. 5. Results of redundancy analysis. Arrows represent pulse properties. Black arrows show response variables; red arrows indicate independent variables. $R_{\mathrm{S} \text {-max }}$, maximum microbial respiration rate; $T_{R_{\mathrm{S} \text { max }}}$, time to reach $R_{\mathrm{S} \text {-max }} ; A_{R_{\mathrm{S}-\text { sip }}}$, accumulative microbial respiration per gram of soil; $A_{R_{\mathrm{S}-\mathrm{soc}}}$, accumulative microbial respiration per gram of soil organic carbon; Duration, duration of the pulse effect from the start to the end of $1 / 2 R_{\mathrm{S}}$ max. LC, litter carbon content; LN, litter nitrogen content; TN, soil total nitrogen; SOC, soil organic carbon content; ORP, oxidation-reduction potential; COND, conductive; PLFA, phospholipid fatty acid-the sum of all PLFAs was used to represent the viable microbial biomass; Ba, bacteria; Fu, fungi; Ac, actinomycetes.

than those of previous studies, which have reported increases of fourfold (Fierer and Schimel, 2003) up to 10-fold (Casals et al., 2009). On the other hand, consistent with the finding of Sponseller (2007), the pulse effect of simulated precipitation returned to background levels within $48 \mathrm{~h}$. The previous status of soil water content and precipitation intensity may influence the observed pulse effects. Fischer (2009) proposed that the observed pulse effects were derived from the soils being insufficiently dry or reaching the drying threshold to restrict microbial growth. Soils that were extremely dry inhibited dormancy of soil microbes, whereas microbial growth was rapid in even slightly moist soils. The differences in initial SWC may therefore influence the observed precipitation pulse properties. In future studies, the previous soil water condition (or drying threshold) should be evaluated. The pulse effect may also be influenced by the measurement interval. Previous studies used measurement intervals of several hours or days (Casals et al., 2009; Fierer and Schimel, 2003; Meisner et al., 2015). Hence, when comparing different studies, we should consider differences in precipitation intensity, previous soil water condition and measurement interval. At the same time, it is necessary to further investigate and quantify the effect of a single variable on the precipitation pulse of air dried soil in order to obtain in-depth knowledge about precipitation pulse and soil $\mathrm{C}$ dynamics.

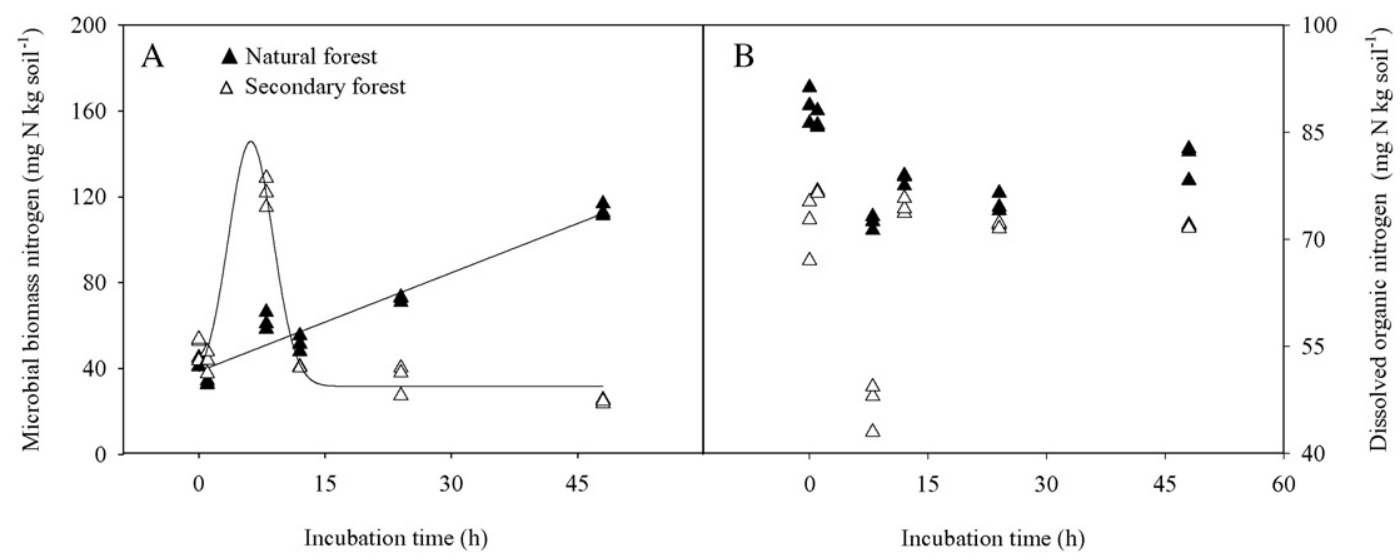

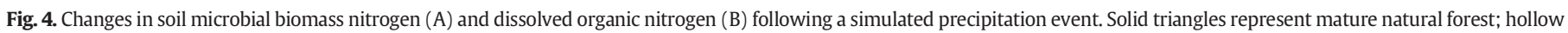
triangles represent degraded secondary forest. 


\subsection{Influence of forest type on the pulse effects of precipitation}

The pulse effects of precipitation on $R_{\mathrm{S}}$ were more marked in mature natural forest soil than in degraded secondary forest soil. The variation in soil microbial biomass observed in this study could be a partial explanation for the observed pulse effects. In a previous study by Lundquist et al. (1999), respiration positively increased with microbial biomass. Meanwhile, Kim et al. (2012) hypothesized that substrate supply enhanced microbial metabolism, based on a new database of 338 studies conducted from 1956 to 2011. This hypothesis parallels our study but is different from that of Meisner et al. (2013) who have shown that microbial growth is uncoupled from the initial respiration pulse, and that growth responses and microbial C-use efficiency can be affected by prolonged drying. The fact that this microbial effect has not yet reached a consensus may be attributed to prolonged drought or perhaps variance in soil conditions before air drying or rewetting (Meisner et al., 2015).

Another important explanation for the strong and rapid pulse effect may be the rapid increase of the accessible substrate. In this study, the $\mathrm{RDA}$ results revealed that $R_{\mathrm{S}}$ was negatively correlated with litter $\mathrm{C}$ content and positively correlated with litter $\mathrm{N}$ content (Fig. 5), thereby verifying the important influence of soil substrate on the observed pulse effects. Jones and Murphy (2007) have reported the vital function of adding substrate to microbe that the response of microbial respiration to substrate addition occurred almost instantaneously $(<60 \mathrm{~s})$, and that the average times to half-maximum $\mathrm{CO}_{2}$ production for glucose and glycine were $14 \pm 8 \mathrm{~min}$ and $10 \pm 8 \mathrm{~min}$, respectively. In addition, $\mathrm{He}$ and Yu (2016) found that microbial respiration rate was exponentially correlated to substrate stoichiometry ( $\mathrm{N}: \mathrm{C}$ ratio) in both grassland and forest soils. The important effect of stoichiometry ( $\mathrm{N}: \mathrm{C}$ ratio) of added substrates on SOM decomposition may alter the relative availability of $\mathrm{C}$ - and $\mathrm{N}$-feeding soil microbes owing to the imbalance of $\mathrm{C}$ and $\mathrm{N}$ availability in soil. On the basis of the results obtained by Jones and Murphy (2007) and He and Yu (2016), we hypothesized that precipitation plays an important role in the availability of decomposed substrate to microbe. However, because the ratio of $\mathrm{N}: \mathrm{C}$ (microbial biomass $\mathrm{C}: \mathrm{N}$ or dissolved organic $\mathrm{C}: \mathrm{N}$ ) was not measured in this study, we cannot draw a conclusion to explain the particular effect on the difference in precipitation pulse.

The pulse effects of precipitation on $R_{\mathrm{S} \text {-max }}$ were more marked in degraded secondary forest soil than in mature natural forest soil; however, a contrasting effect was observed for $T_{R_{s-\max }}$. Based on our RDA results, we inferred that these contrasting patterns are derived from differences in soil texture. Sand stabilizes occluded organic matter against microbial decomposition less effectively than do silt and clay; hence, in soils with higher sand content, organic matter is more easily accessible within the soil matrix and the SOC content is associated with $T_{R_{s-\max }}$. In addition, we found that microbial biomass $\mathrm{N}$ was quite low with higher dissolved organic $\mathrm{N}$ both in natural and secondary forest at the onset (before precipitation, Fig. 4). Simultaneously, we observed that microbial respiration rate was low at the onset (before precipitation, Fig. 1). However, during precipitation, both microbial biomass $\mathrm{N}$ and microbial respiration rate sharply increased, or the dissolved organic $\mathrm{N}$ sharply declined. In particular, the observed trend of higher microbial respiration rate in secondary forest than in natural forest was in accord with the trend of microbial biomass $\mathrm{N}$. This trend of dissolved organic $\mathrm{N}$ indicates that precipitation plays a more important role in reviving microbes in the secondary forest than those in the natural forest. Microbes in a secondary forest soil utilize large amounts of available dissolved organic $\mathrm{N}$ to synthesize their biomass, which results in $\mathrm{CO}_{2}$ emission at faster speeds. When the decomposition rate and dissolved organic $\mathrm{N}$ levels are too low to meet synthesis requirement, they achieve the maximum respiration rate. These results may partially explain the phenomena that higher $R_{\mathrm{S} \text {-max }}$ and lower $T_{R_{S-\max }}$ are observed in degraded secondary forest soil compared to mature natural forest soil.
The effect of simulated precipitation on the duration of the pulse effect was more marked in the mature natural forest soil than in the degraded secondary forest soil. The results of RDA analyses and the Monte Carlo test revealed that the duration of the pulse effect was mainly related to litter $\mathrm{N}$ content, litter $\mathrm{C}$ content, and soil texture. The important role of soil texture in determining the occurrence and magnitude of pulse dynamics has been reported by many groups (Butterly et al., 2010; Tian et al., 2014). Kaiser et al. (2015) showed that soils with high clay content lost soil moisture more slowly than soils with high sand content, and thus microorganisms had more time to adapt or respond to decreases in soil water content. However, in this study, the mature natural forest soil had higher SOC and TN, whereas the degraded forest soil had higher clay content (Table 1); hence, the duration of the pulse effect was more marked in mature natural forest soil than in degraded secondary forest soil.

The time to recovery of $R_{\mathrm{S}}$ after the simulated precipitation event was more rapid in the degraded secondary forest soil (1.3 days) than in the natural forest soil (2 days). The most likely explanation for this observation is that the natural forest soil had higher SOC content (or a better substrate supply) (Table 1 ), and that this facilitated microbial growth over a longer period. The sharp decline in microbial biomass $\mathrm{N}$ and the shorter duration of the pulse effect in degraded secondary forest soil may be explained as follows. In the process of dry-rewetting-drying, substrates and dead microbial biomass may rapidly become available for surviving microbes through decomposition. Thus, microbial activity can rapidly be reactivated after simulated precipitation; thereafter, a portion of the microbial biomass may die and lyse because of prolonged drying and substrate depletion (Clein and S, 1994; Fierer and Schimel, 2003; van Gestel et al., 1991).

\subsection{Combined effects of substrate and microbes on $A_{R S}$}

The importance of substrate and microbes on $R_{\mathrm{S}}$ has previously been demonstrated (Wu and Brookes, 2005). In this study, $A_{R_{\text {s-soc }}}$ and not $A_{R_{\text {s-soil }}}$ was significantly higher in degraded secondary forest soil than in mature natural forest soil. Previous studies have reported higher $\mathrm{CO}_{2}$ release in soils with lower SOC content (Jensen et al., 2003; Shi and Marschner, 2015), which implies that assessing the precipitation pulse by using SOC as the unit could reveal the SOM decomposition of substrates of different quality in response to precipitation. Jones and Murphy (2007) have observed instantaneous activation of the soil microbial community (evaluated by measuring the $R_{\mathrm{S}}$ value) in response to glucose and glycine addition, which further indicated the importance of substrate on $R_{\mathrm{S}}$. In this study, the RDA results revealed that litter $\mathrm{C}$ and $\mathrm{N}$ content were strongly correlated with variation in $A_{R_{\mathrm{S}-\mathrm{soc}}}$ (Fig. 5), which verified the vital effect of substrate.

Fierer and Schimel (2003) showed that the $\mathrm{CO}_{2}$ pulse was generated from the decay of microbial biomass without significant lysis of microbial cells using 14C-enriched glucose. In accordance with the results of Fierer and Schimel (2003), we found that in mature natural forest, $A_{R_{\text {s-soi }}}$ was as many as the enrichment of microbial biomass $\mathrm{N}$ pool but 1.4 -fold higher than the enrichment of dissolved organic $\mathrm{N}$ content. In the degraded secondary forest, $A_{R_{\mathrm{s}-\text { soil }}}$ was 4.6 -fold higher than the enrichment of the microbial biomass $\mathrm{N}$ pool and 1.6-fold higher than the enrichment of dissolved organic N. Hence, we assume that the observed variation in $A_{\mathrm{RS}}$ between the two forest soils may be derived partially from the decomposition of SOM and microbes. Based on the studies of Fierer and Schimel (2003) and Schimel et al. (2011), future studies will require the use of isotope tracer techniques to fully quantify the effects of substrate and microbes on $A_{\mathrm{RS}}$.

\section{Conclusion}

In this study, we demonstrated that the pulse effects of precipitation on soil microbial respiration are stronger and more rapid in secondary forest soils than that in natural forest soils. Poor soil conditions (with 
regard to the quality and quantity of substrate) may be a critical factor for the significant differences observed between the two forest types. Under conditions of high desertification and unexpected precipitation, the characteristic of response of secondary forest to precipitation (i.e., a sharp response and high $\mathrm{CO}_{2}$ accumulation) may play an important role in the future global climate change. According to our results, high-frequency measurement technologies may be an efficient way to assess the pulse effects of precipitation events. Furthermore, the unit per gram $C$ to depict soil microbial respiration may better demonstrate the effect of soil substrate quality on microbial respiration.

\section{Acknowledgements}

This work was partially supported by the Major Program of the National Natural Science Foundation of China (No. 41571130043, 31470506, 31290221), and the Program for Kezhen Distinguished Talents in Institute of Geographic Sciences and Natural Resources Research, Chinese Academy of Sciences (2013RC102). Data share should be contacted with Dr. N. P. He (E-mail: henp@igsnrr.ac.cn).

\section{References}

Baath, E., Anderson, T.H., 2003. Comparison of soil fungal/bacterial ratios in a pH gradient using physiological and PLFA-based techniques. Soil Biol. Biochem. 35, 955-963.

Birch, H.F., 1958. The effect of soil drying on humus decomposition and nitrogen availability. Plant Soil 10, 9-31.

Brookes, P.C., Kragt, J.F., Jenkinson, D.S., 1985. Chloroform fumigation and the release of soil nitrogen: a rapid direct extraction method to measure microbial biomass nitrogen in soil. Soil Biol. Biochem. 17, 837-842.

Butterly, C.R., Bunemann, E.K., McNeill, A.M., Baldock, J.A., Marschner, P., 2009. Carbon pulses but not phosphorus pulses are related to decreases in microbial biomass during repeated drying and rewetting of soils. Soil Biol. Biochem. 41, 1406-1416.

Butterly, C.R., Marschner, P., McNeill, A.M., Baldock, J.A., 2010. Rewetting $\mathrm{CO}_{2}$ pulses in Australian agricultural soils and the influence of soil properties. Biol. Fertil. Soils 46, 739-753.

Cable, J.M., Huxman, T.E., 2004. Precipitation pulse size effects on Sonoran Desert soil microbial crusts. Oecologia 141, 317-324.

Casals, P., Gimeno, C., Carrara, A., Lopez-Sangil, L., Sanz, M.J., 2009. Soil $\mathrm{CO}_{2}$ efflux and extractable organic carbon fractions under simulated precipitation events in a Mediterranean Dehesa. Soil Biol. Biochem. 41, 1915-1922.

Chowdhury, N., Yan, N., Islam, M.N., Marschner, P., 2011. The extent of drying influences the flush of respiration after rewetting in non-saline and saline soils. Soil Biol. Biochem. 43, 2265-2272.

Clein, J., S, J., 1994. Reduction in microbial activity in birch litter due to drying and rewetting event. Soil Biol. Biochem. 26, 403-406.

Cui, M.Y., Caldwell, M.M., 1997. A large ephemeral release of nitrogen upon wetting of dry soil and corresponding root responses in the field. Plant Soil 191, 291-299.

Davidson, E.A., Verchot, L.V., C, J.H., Ackerman, I.L., Carvalho, J.E.M., 2000. Effects of soil water content on soil respiration in forests and cattle pastures of eastern Amazonia. Biochemistry 48, 53-69.

Evans, S.E., Wallenstein, M.D., 2012. Soil microbial community response to drying and rewetting stress: does historical precipitation regime matter? Biogeochemistry 109 $101-116$

Fierer, N., Schimel, J.P., 2003. A proposed mechanism for the pulse in carbon dioxide production commonly observed following the rapid rewetting of a dry soil. Soil Sci. Soc. Am. J. 67, 798-805.

Fischer, T., 2009. Substantial rewetting phenomena on soil respiration can be observed at low water availability. Soil Biol. Biochem. 1577-1579.

Göransson, H., Godbold, D.L., Jones, D.L., Rousk, J., 2013. Bacterial growth and respiration responses upon rewetting dry forest soils: impact of drought-legacy. Soil Biol. Biochem. 57, 477-486.

He, N.P., Yu, G.R., 2016. Stoichiometrical regulation of soil organic matter decomposition and its temperature sensitivity. Ecol. Evol. http://dx.doi.org/10.1002/ece3.1927.

He, N.P., Wang, R.M., Gao, Y., Dai, J.Z., Wen, X.F., Yu, G.R., 2013. Changes in the temperature sensitivity of SOM decomposition with grassland succession: implications for soil C sequestration. Ecol. Evol. 3, 5045-5054.

He, N.P., Wu, L., Wang, Y.S., Han, X.G., 2009. Changes in carbon and nitrogen in soil particle-size fractions along a grassland restoration chronosequence in northern China. Geoderma 150, 302-308.

Hou, J.H., Mi, X.C., Liu, C.R., Ma, K.P., 2006. Tree competition and species coexistence in a Quercus-Betula forest in the Dongling Mountains in northern China. Acta Oecol. 30, $117-125$
Huxman, T.E., Snyder, K.A., Tissue, D., Leffler, A.J., Ogle, K., Pockman, W.T., Sandquist, D.R., Potts, D.L., Schwinning, S., 2004. Precipitation pulses and carbon fluxes in semiarid and arid ecosystems. Oecologia 141, 254-268.

Iovieno, P., Baath, E., 2008. Effect of drying and rewetting on bacterial growth rates in soil. FEMS Microbiol. Ecol. 65, 400-407.

Jensen, K.D., Beier, C., Michelsen, A., Emmett, B.A., 2003. Effects of experimental drought on microbial processes in two temperate heathlands at contrasting water conditions. Appl. Soil Ecol. 24, 165-176.

Jones, D.L., Murphy, D.V., 2007. Microbial response time to sugar and amino acid additions to soil. Soil Biol. Biochem. 39, 2178-2182.

Kaiser, M., Kleber, M., Berhe, A.A., 2015. How air-drying and rewetting modify soil organic matter characteristics: an assessment to improve data interpretation and inference. Soil Biol. Biochem. 80, 324-340.

Kim, D.G., Vargas, R., Bond-Lamberty, B., Turetsky, M.R., 2012. Effects of soil rewetting and thawing on soil gas fluxes: a review of current literature and suggestions for future research. Biogeosciences 9, 2459-2483.

Lundquist, E.J., Jackson, L.E., Scow, K.M., 1999. Wet-dry cycles affect dissolved organic carbon in two California agricultural soils. Soil Biol. Biochem. 31, 1031-1038.

Manzoni, S., Schaeffer, S.M., Katul, G., Porporato, A., Schimel, J.P., 2014. A theoretical analysis of microbial eco-physiological and diffusion limitations to carbon cycling in drying soils. Soil Biol. Biochem. 73, 69-83.

Meisner, A., Baath, E., Rousk, J., 2013. Microbial growth responses upon rewetting soil dried for four days or one year. Soil Biol. Biochem. 66, 188-192.

Meisner, A., Rousk, J., Bååth, E., 2015. Prolonged drought changes the bacterial growth response to rewetting. Soil Biol. Biochem. 88, 314-322.

Miller, A.E., Schimel, J.P., Meixner, T., Sickman, J.O., Melack, J.M., 2005. Episodic rewetting enhances carbon and nitrogen release from chaparral soils. Soil Biol. Biochem. 37, 2195-2204.

Ostfeld, R.S., Keesing, F., 2000. Pulsed resources and community dynamics of consumers in terrestrial ecosystems. Trends Ecol. Evol. 15, 232-237.

Phillips, J.D., Marion, D.A., 2007. Soil geomorphic classification, soil taxonomy, and effects on soil richness assessments. Geoderma 141, 89-97.

Roscoe, R., Buurman, P., Velthorst, E.J., 2000. Disruption of soil aggregates by varied amounts of ultrasonic energy in fractionation of organic matter of a clay Latosol: carbon, nitrogen, and $\delta^{13} \mathrm{C}$ distribution in particle-size fractions. Eur. J. Soil Sci. 51, 445-454.

Rudaz, A.O., Davidson, E.A., Firestone, M.K., 1991. Sources of nitrous-oxide production following wetting of dry soil. FEMS Microbiol. Ecol. 85, 117-124.

Sala, O.E., Lauenroth, W.K., 1982. Small rainfall events: an ecological role in semiarid regions. Oecologia 53, 301-304.

Schimel, J.P., Wetterstedt, J.Å.M., Holden, P.A., Trumbore, S.E., 2011. Drying/rewetting cycles mobilize old $\mathrm{C}$ from deep soils from a California annual grassland. Soil Biol. Biochem. 43, 1101-1103.

Schwinning, S., Sala, O.E., 2004a. Hierarchy of responses to resource pulses in arid and semi-arid ecosystems. Oecologia 141, 211-220.

Schwinning, S., Sala, O.E., Loik, M.E., Ehleringer, J.R., 2004b. Thresholds, memory, and seasonality: understanding pulse dynamics in arid/semi-arid ecosystems. Oecologia 141, 191-193.

Schwinning, S., Starr, B.I., Ehleringer, J.R., 2003. Dominant cold desert plants do not partition warm season precipitation by event size. Oecologia 136, 252-260.

Shi, A.D., Marschner, P., 2014. Drying and rewetting frequency influences cumulative respiration and its distribution over time in two soils with contrasting management. Soil Biol. Biochem. 72, 172-179.

Shi, A.D., Marschner, P., 2015. The number of moist days determines respiration in drying and rewetting cycles. Biol. Fertil. Soils 51, 33-41.

Sponseller, R.A., 2007. Precipitation pulses and soil $\mathrm{CO}_{2}$ flux in a Sonoran desert ecosystem. Glob. Chang. Biol. 13, 426-436.

Tian, Q.X., He, H.B., Cheng, W.X., Zhang, X.D., 2014. Pulse-dynamic and monotonic decline patterns of soil respiration in long term laboratory microcosms. Soil Biol. Biochem. 68, 329-336.

van Gestel, M., Ladd, J.N., Amato, M., 1991. Carbon and nitrogen mineralization from two soils of contrasting texture and microaggregate stability: influence of sequential fumigation, drying and storage. Soil Biol. Biochem. 23, 313-322.

Wang Q, He, N.P., Yu, G.R., Gao, Y, Wen, X.F, Wang R.F, Koerner, S.E, Yu, Q, 2016. Soil microbial respiration rate and temperature sensitivity along a North-South forest transect in eastern China: patterns and influencing factors. J. Geophys. Res. Biogeosci. http://dx.doi.org/10.1002/2015JG003217.

Wu, J., Brookes, P.C., 2005. The proportional mineralisation of microbial biomass and organic matter caused by air-drying and rewetting of a grassland soil. Soil Biol. Biochem. 37, 507-515.

Xu, Z.W., Yu, G.R., Zhang, XY, Ge, J.P. He, N.P., Wang Q.F. Wang, D. 2015. The variations in soil microbial communities, enzyme activities and their relationships with soil organic matter decomposition along the northern slope of Changbai Mountain. Appl. Soil Ecol. 86, 19-29. 